\title{
International Conference on "Dependence Modelling: Statistical Theory and Applications to Finance and Insurance" (DEMOSTAFI) 20-22 May 2004 in Quebec City, Canada
}

This conference is a sequel to the series of conferences on copulas, dependence models and their applications that were held in Rome (1990), Seattle (1993), Prague (1996) and Barcelona (2000).

The purpose of this conference is to bring together researchers interested in modelling stochastic dependence and measuring its effects in statistics, actuarial science and finance. The meeting aims to attract copula specialists and statistical researchers interested in their development and use in characterizing and modelling of dependence (stochastic orderings, distributions with fixed marginals, etc.). We would also like to put emphasis on applications of the relevant concepts and inferential techniques in the fields of actuarial science and finance, which are thriving at present. The "technological transfer" aspect of the conference will be especially important; for example, several survey talks by world specialists have been planned.

For additional information about this meeting, registration material and so on, please visit the conference website at http://www.fsa.ulaval.ca/demostafi/

Etienne Marceau, Ph. D., A.S.A.

Member of the organizing committee

Associate Professor

Ecole d'Actuariat

Laval University

Quebec (Que)

Canada, G1K 7P4

Phone: (418) 656-2013

Fax: (418) 656-7790

email: emarceau@act.ulaval.ca

website: http://hyperion.act.ulaval.ca/ emarceau/ 